\title{
Ontogenetic differentiation of swimming performance and behaviour in relation to habitat availability in the endangered North Sea houting (Coregonus oxyrinchus)
}

\author{
Søren Brandt Poulsen ${ }^{1, a, b}$, Lasse Fast Jensen ${ }^{1}$, Carsten SCHUlz $^{2,3}$, Michael DeACON $^{4}$, \\ Knud Erik MEYER ${ }^{5}$, Tassilo JÄGER-KLEINICKE ${ }^{6}$, Helmut SCHWARTEN ${ }^{7}$ and Jon Christian SvENDSEN $^{8,9}$ \\ 1 Fisheries and Maritime Museum, 6710 Esbjerg V, Denmark \\ ${ }^{2}$ Christian-Albrechts-Universität zu Kiel, Institute for Animal Breeding and Husbandry, 24098 Kiel, Germany \\ 3 Gesellschaft für Marine Aquakultur (GMA) mbH, 25761 Büsum, Germany \\ ${ }^{4}$ Danish Ministry of the Environment, Ribe Environmental Centre, Water and Nature Division, 6760 Ribe, Denmark \\ 5 Technical University of Denmark, Department of Mechanical Engineering, 2800 Kgs, Lyngby, Denmark \\ 6 Tassilo Jäger-Kleinicke, 24147 Kiel, Germany \\ 7 Fisheries Helmut Schwarten, 23714 Malente, Germany \\ 8 Technical University of Denmark, National Institute of Aquatic Resources, Freshwater Fisheries, 8600 Silkeborg, Denmark \\ 9 University of Copenhagen, Marine Biological Laboratory, Biological Institute, 3000 Helsingør, Denmark
}

Received 11 September 2011; Accepted 23 May 2012

\begin{abstract}
The survival of the highly endangered, anadromous fish species North Sea houting (Coregonus oxyrinchus) depends on the correct timing of downstream dispersal during its early ontogenetic stages. To date, however, no studies have investigated the ontogenetic differentiation of swimming performance and behaviour, including the potential of habitat complexity to influence dispersal rates. By testing larval and juvenile North Sea houting in a laboratory, we examined (1) swimming performance measured as maximum swimming performance $\left(U_{\max }\right)$ and routine swimming speed $\left(U_{\text {routine }}\right)$ and (2) the potential of habitat complexity (i.e., cover providing shade) to influence dispersal behaviour in an indoor stream channel. The $U_{\max }$ and the $U_{\text {routine }}$ were 9.4 and $4.6 \mathrm{~cm} \mathrm{~s}^{-1}$, respectively, in the larvae [body length $(B L) \mathrm{s}^{-1}: 7.3$ and 3.5, respectively], and 25.2 and $16.3 \mathrm{~cm} \mathrm{~s}^{-1}$ in the juveniles (BL s $\mathrm{s}^{-1}: 7.0$ and 5.2, respectively). We compared laboratory swimming performance data with water speeds in North Sea houting spawning areas in the Danish River Vidaa. Results showed that the water speeds present in $95 \%$ and $85 \%$ of the water column caused downstream displacement of larvae and juveniles, respectively. However, areas with slow-flowing water near river banks and river beds could function as nursery habitats. Stream channel experiments showed that cover providing shade caused delayed dispersal in both larvae and juveniles, but the larvae dispersed later and spent less time under cover than the juveniles, a finding that implies ontogenetic effects. Finally, the larvae refused to cross an upstream-positioned cover, a behaviour that was not observed in the juveniles. Therefore, habitat complexity may have the potential to influence dispersal behaviour in both larval and juvenile North Sea houting. Overall, we provided the first evidence of ontogenetic differentiation in the North Sea houting. These findings will be valuable for the development and dissemination of science-based conservation strategies.
\end{abstract}

Keywords: Conservation / Fish behaviour / Early life history / Nursery habitat / Management / Coregonid / Salmonid / Wadden Sea

\section{Introduction}

Newly-hatched salmonid larvae may be challenged by high flow conditions. Salmonid species such as brown trout (Salmo trutta) and Atlantic salmon (Salmo salar) reduce the risk of

\footnotetext{
${ }^{a}$ Corresponding author: sbp@fimus.dk

b Present address: The Water and Salt Research Centre, Department of Biomedicine, Aarhus University, 8000 Aarhus C, Denmark
}

downstream displacement by depositing their eggs in nests during spawning. Upon hatching, the larvae spend their first three to eight weeks in these nests before they emerge and start their life stage in lotic environments (Aas et al. 2011). At the point of emergence, the critical water speed that causes downstream displacement is $10 \mathrm{~cm} \mathrm{~s}^{-1}$ to $25 \mathrm{~cm} \mathrm{~s}^{-1}$, but this speed varies among individuals and depends on species and water temperature (Heggenes and Traaen 1988). Downstream displacement may be lethal to newly emerged salmonids and contribute substantially to first year mortality (Saltveit et al. 1995; 
Jensen and Johnsen 1999; Cattanéo et al. 2003; Wenger et al. 2011).

In contrast to Atlantic salmon and brown trout, most coregonids such as the North Sea houting (Coregonus oxyrinchus) spawn freely in water, with their eggs adhering to gravel and vegetation. Upon hatching, the offspring of free-spawning species may potentially drift for substantial distances, because many larvae possess poorly developed locomotor capabilities compared with fry emerging from their nests (Lucas and Baras et al. 2001).

The upstream migration performed by mature adults may counteract the downstream dispersal of the offspring in early life stages (Lucas and Baras et al. 2001). However, access to upstream spawning areas is often obstructed by barriers such as weirs and dams (Jensen et al. 2003; Aas et al. 2011) that force mature fish to spawn in downstream regions (Jensen et al. 2003). This condition may be detrimental to the offspring because they are likely to be displaced prematurely into the marine environment.

The North Sea houting is a highly endangered anadromous coregonid species (Stoltze and Pihl 1998) endemic to the Wadden Sea (Jensen et al. 2003). In late autumn, adult North Sea houting migrate from the Wadden Sea into the rivers to spawn (Hvidt and Christensen 1990; Jensen et al. 2003). Successful reproduction depends on the spawning areas, which should contain dense aquatic macrophytes in winter and should be covered by stones or gravel to which the eggs can attach. The eggs hatch in the early spring, and the young North Sea houting remain in the river until April or May by which time they will have reached $3 \mathrm{~cm}$ to $5 \mathrm{~cm}$ in total length (Rasmussen 2004). At this point, most start their migration into the Wadden Sea. Premature arrival at sea is lethal for both larval and juvenile North Sea houting (Thomsen 2003; Jensen et al. 2003), so survival in the early life stages depends on habitats that allow the fish to remain in the nursery areas of the river (Jensen et al. 2003).

Historically, the North Sea houting was distributed across the entire Wadden Sea area, which is bordered by Germany, the Netherlands and Denmark. By the 1930s, the North Sea houting disappeared entirely from Germany and the Netherlands because of severe pollution, migratory barriers, fishing and eradication of spawning and nursery areas. A recent study showed that eutrophication plays a similar role in a number of whitefish species (Vonlanthen et al. 2012). By the 1970s and 1980s, remaining populations of the North Sea houting were extirpated from all Danish rivers except the River Vidaa $\left(54^{\circ} 55^{\prime} \mathrm{N} ; 8^{\circ} 52^{\prime} \mathrm{E}\right)$. At this point, the species was on the brink of becoming extinct (Jensen et al. 2002; Borcherding et al. 2006; Madsen and Murray 2007; Hansen et al. 2008).

Although the North Sea houting is broadly acknowledged as an endangered species, its taxonomic status has become controversial. Freyhof and Schöter (2005) suggested that the North Sea houting was confined to the region of the Rhine River and is now extinct, a conclusion that has been adopted by the International Union for the Conservation of Nature. However, the study of Freyhof and Schöter (2005) focused on morphological traits that are highly homeoeplastic in whitefish (Bernatchez et al. 1996; Østbye et al. 2005, 2006; Etheridge et al. 2012). Therefore, the conclusion of extinction is considered disputable (Jacobsen et al. 2012).

In an effort to save the North Sea houting, a large-scale restoration program was initiated in 2005 , aiming to restore the species to a favourable conservation status. The program facilitates the free upstream migration of adult North Sea houting and promotes larval and juvenile survival by establishing spawning and nursery areas (Jensen et al. 2003). The early life stages are particularly critical for the survival of the species (Jensen et al. 2003; Madsen and Murray 2007; Borcherding et al. 2006; Hansen et al. 2008). However, the ecology, behaviour and habitat requirements and the potential linkage between habitat availability and downstream dispersal of larval and juvenile fish remain unknown. Therefore, insights into the swimming performance and behaviour of the North Sea houting in its early life stages are needed to determine the potential benefits of habitat restoration.

We investigated ontogenetic differentiation in the early life stages of the North Sea houting to identify the direct implications of this differentiation to the conservation and management of this endangered fish species. Specifically, we examined swimming performance and the link between habitat complexity and the tendency of the species to disperse. The following variables were tested: (1) swimming performance measured as maximum swimming performance $\left(U_{\max }\right)$ and routine swimming speed $\left(U_{\text {routine }}\right)$ and (2) potential of habitat complexity (i.e., cover providing shade) to modify dispersal behaviour in an indoor stream channel. By comparing laboratory swimming performance data with water speed data from North Sea houting spawning areas in the Danish River Vidaa, we aimed to identify whether the spawning areas could function as nursery habitats for newly-hatched larvae and juveniles without causing downstream displacement.

\section{Materials and methods}

\subsection{Experimental fish}

Experiments were conducted at the Research and Technology Centre Westcoast, University of Kiel, Büsum, Germany. Larval and juvenile North Sea houting (one to two and seven to eight weeks old, respectively) were obtained from a commercial hatchery (Malente, Germany) that uses adults caught in the River Vidaa for breeding purposes. Fish were kept indoors in an ambient light regime [April (14L:10D) to June (17L:7D)] in holding tanks supplied with recirculated tap water [mean temperature: $10.3{ }^{\circ} \mathrm{C}$ (range $99{ }^{\circ} \mathrm{C}$ to $108{ }^{\circ} \mathrm{C}$ )]. Larvae were fed with a diet of commercial rearing food six times a day, whereas juveniles were fed with a diet of frozen Chironomus sp. larvae (Borcherding et al. 2006) three times a day.

\subsection{Experimental setups}

\subsubsection{Swim tunnel}

A mini swim tunnel was used (Loligo Systems APS, Tjele, Denmark) to measure the maximum swimming performance $\left(U_{\max }\right)$. The inner dimensions of the cylindrical observation 
section were $2.6 \mathrm{~cm} \times 10.0 \mathrm{~cm}$ (diameter and length, respectively). An impeller, placed downstream of the observation section, was driven by an external electric motor that generated a re-circulating flow. Deflectors, situated upstream of the observation section, collimated the flow. Water passed through an upstream honeycomb $(0.2 \mathrm{~cm}$ cell diameter $)$ to promote rectilinear flow and a uniform water speed profile in the observation section; a micro turbulent flow was produced. The observation section was bounded by a grid $(0.1 \mathrm{~cm} \times 0.1 \mathrm{~cm})$ in both upstream and downstream directions. Water speeds in the observation section were measured with a laser doppler velocimeter (Albrecht et al. 2003) consisting of a $4 \mathrm{~W}$ Ar-ion laser, a Fiberprobe and BSA data processors (Dantec Dynamics, Skovlunde, Denmark). The equipment used small particles naturally occurring in tap water as seeding particles. Water speeds were confirmed repeatedly by video tracking of neutrally buoyant particles and dye. The measurements were used to correlate water speed to voltage output from the external motor controller. In addition, because the body of a fish in the observation section obstructs the cross-sectional area, water flows at a fast speed around the fish. Therefore, solid blocking correction in accordance with the methods of Bell and Terhune (1970) and Gehrke et al. (1990) was performed preceding the tests.

\subsubsection{Indoor stream channel}

Fish were tested in two identical indoor stream channels, in a way similar to the method of Vehanen (2000), to investigate the $U_{\text {routine }}$ and the dispersal tendency in response to habitat modification. The $400 \mathrm{~cm}$-long, $20 \mathrm{~cm}$-wide (inner diameter) stream channels were half-tubular and had a smooth bottom to minimise the thickness of the boundary layer. The water speed in the stream channels was $4 \mathrm{~cm} \mathrm{~s}^{-1}$. Additional details were published in our previous work (Poulsen et al. 2010).

\subsection{Test procedures}

For all tests, individual fish were transferred from the holding tank to the experimental setup (swim tunnel or stream channel) using a small container (0.3 1). To minimise stress, the fish were guided into the container without any contact with air.

\subsection{1 $U_{\max }$}

Before testing, the individual fish were starved for $15 \mathrm{~h}$ to $25 \mathrm{~h}$ and then acclimated in the swim tunnel for $15 \mathrm{~min}$ (Guan et al. 2008; Koumoundouros et al. 2009) at a water speed of $1.5 \mathrm{~cm} \mathrm{~s}^{-1}$. Subsequently, the swimming speed was increased by $0.5 \mathrm{~cm} \mathrm{~s}^{-1}$ every $30 \mathrm{~s}$ until the fish were fatigued and could no longer maintain their position, which was defined as incapability to move away from the downstream grid (Bushnell et al. 1994). Recent studies show that the $U_{\max }$ swimming protocol provides measurements that are repeatable in individual fish (Oufiero and Garland 2009). The short-speed step duration (30 s) used in our $U_{\max }$ protocol (Farrell 2008) means that the energy expenditure is partly covered by anaerobic metabolism. By contrast, the long duration of the speed steps used in conventional $U_{\text {crit }}$ protocol means that the energy expenditure is mostly covered by aerobic metabolism. The $U_{\text {crit }}$ protocol provides measurements of maximum prolonged swimming performance (Farrell 2007). The $U_{\max }$ was calculated in the same manner as $U_{\text {crit }}$ (Brett 1964) because the two protocols only differ in speed step duration. The test involved 12 larvae [mean $\pm \mathrm{SE}, B L: 1.3 \pm 0.1 \mathrm{~cm}$ (range: $1.1 \mathrm{~cm}$ to $1.4 \mathrm{~cm}$ ); mass: $7 \pm$ $1 \mathrm{mg}$ (range: $5 \mathrm{mg}$ to $9 \mathrm{mg}$ )] and 12 juveniles $[B L: 3.6 \pm 0.1 \mathrm{~cm}$ (range: $3.3 \mathrm{~cm}$ to $3.9 \mathrm{~cm}$ ); mass: $259 \pm 16 \mathrm{mg}$ (range: $192 \mathrm{mg}$ to $375 \mathrm{mg}$ )]. The mean temperature in the swim tunnel was $10.3{ }^{\circ} \mathrm{C}$ (range: $9.9^{\circ} \mathrm{C}$ to $10.5^{\circ} \mathrm{C}$ ).

\subsubsection{Dispersal and response to habitat modification}

Indoor stream channels were used to investigate the dispersal behaviour of North Sea houting, in accordance with the methods used in previous studies (Wilzbach 1985; Mesick 1988; Crisp 1991; Crisp and Hurley 1991a, 1991b; Rehage and Sih 2004; Cote et al. 2010). We aimed to determine whether habitat complexity (i.e., cover providing shade) could be a conservation tool to delay dispersal. Shade was provided by a downstream and an upstream cover (length: $44.5 \mathrm{~cm}$; width: $20 \mathrm{~cm}$ ) positioned $2 \mathrm{~cm}$ above the water surface (Pusey and Arthington 2003). For $15 \mathrm{~min}$ ahead of data collection, individual fish were acclimated to the indoor stream (Krause et al. 1998, 1999) in a transparent chamber (length: $8 \mathrm{~cm}$; width: $4 \mathrm{~cm}$; height: $8 \mathrm{~cm}$ ) positioned centrally between the two covered areas. Trials were started by lifting the acclimation chamber and were ended when the fish crossed the downstream or the upstream border, each situated $200 \mathrm{~cm}$ from the central release point. The following variables were quantified: (1) time (s) spent in the experimental section before dispersing (i.e., time elapsed before the fish crossed the upstream or the downstream border, in accordance with Mesick 1988), 2) percentage of time spent under cover and (3) number of fish passing the upstream or the downstream covered area. If a fish stayed within the upstream and the downstream borders for $>2700 \mathrm{~s}$ (45 min), the trial was terminated, and $2700 \mathrm{~s}$ was noted as the time spent in the experimental section before dispersal. The tests included 20 larvae $[B L: 1.3 \pm 0.1 \mathrm{~cm}$ (range: $1.1 \mathrm{~cm}$ to $1.4 \mathrm{~cm}$ ); mass: $7 \pm 1 \mathrm{mg}$ (range: $5 \mathrm{mg}$ to $9 \mathrm{mg}$ )] and $30 \mathrm{ju}-$ veniles [BL: $3.3 \pm 0.1 \mathrm{~cm}$ (range: $2.6 \mathrm{~cm}$ to $3.7 \mathrm{~cm}$ ); mass: $190 \pm 13 \mathrm{mg}$ (range: $81 \mathrm{mg}$ to $312 \mathrm{mg}$ )]. Tests without covered areas (i.e., control experiment) were performed with the use of an identical protocol and included 20 larvae [BL: $1.3 \pm$ $0.1 \mathrm{~cm}$ (range: $1.2 \mathrm{~cm}$ to $1.4 \mathrm{~cm}$ ); mass: $8 \pm 1 \mathrm{mg}$ (range: $5 \mathrm{mg}$ to $11 \mathrm{mg}$ )] and 30 juveniles [BL: $3.2 \pm 0.1 \mathrm{~cm}$ (range: $2.6 \mathrm{~cm}$ to $3.9 \mathrm{~cm}$ ); mass: $169 \pm 12 \mathrm{mg}$ (range: $80 \mathrm{mg}$ to $389 \mathrm{mg}$ )] The mean temperature in the experimental setup was $10.0^{\circ} \mathrm{C}$ (range: $9.7{ }^{\circ} \mathrm{C}$ to $10.4{ }^{\circ} \mathrm{C}$ ). Analyses included data from our parallel study (Poulsen et al. 2010) on juvenile North Sea houting testing the effect of cover under identical conditions.

\subsection{3 $U_{\text {routine }}$}

For the measurements of $U_{\text {routine }}$, each stream channel was divided into nine sections measuring $44.5 \mathrm{~cm}$ each. The mean 
$U_{\text {routine }}$ was estimated with upstream swimming through measurement of the time spent from entering a section downstream until leaving it in the upstream direction (measured to the nearest second). The mean $U_{\text {routine }}$ was calculated by division of the section length by the time spent in the section and by subsequent addition of the water speed experienced by the fish $\left(4 \mathrm{~cm} \mathrm{~s}^{-1}\right)$. The tests involved 13 larvae $[B L: 1.3 \pm 0.1 \mathrm{~cm}$ (range: $1.2 \mathrm{~cm}$ to $1.4 \mathrm{~cm}$ ); mass: $7 \pm 1 \mathrm{mg}$ (range: $5 \mathrm{mg}$ to $9 \mathrm{mg}$ )] and 15 juveniles [BL: $3.1 \pm 0.1 \mathrm{~cm}$ (range: $2.7 \mathrm{~cm}$ to $3.9 \mathrm{~cm}$ ); mass: $169 \pm 18 \mathrm{mg}$ (range: $96 \mathrm{mg}$ to $389 \mathrm{mg}$ )]. The mean temperature in the stream channels was $10.0^{\circ} \mathrm{C}$ (range: $9.7{ }^{\circ} \mathrm{C}$ to $10.4{ }^{\circ} \mathrm{C}$ ).

\subsection{Water speed measurements collected in the Danish River Vidaa}

Water speeds in the Danish River Vidaa system were measured at two locations [the River Grønaa ( $54^{\circ} 55^{\prime} \mathrm{N} ; 8^{\circ} 59^{\prime} \mathrm{E}$ ) and the River Sønderaa $\left.\left(54^{\circ} 53^{\prime} \mathrm{N} ; 8^{\circ} 59^{\prime} \mathrm{E}\right)\right]$ to compare the $U_{\max }$ and the $U_{\text {routine }}$ swimming speeds with field water speed data. These locations are known spawning areas of the North Sea houting (Hvidt and Christensen 1990; Jensen et al. 2003) and are characterised by the presence of riverbeds covered by sand and of sparse bottom vegetation. Therefore, the opportunity for young fish to find shelter from currents is limited. Adult North Sea houting were observed upstream of the location in the River Sønderaa (Hvidt and Christensen 1990), but no further data were available for the location in the River Grønaa. Water speeds were measured at various depths (range: $3 \mathrm{~cm}$ to $217 \mathrm{~cm}$ above the river bed, Fig. 2) using a propeller flow-meter (A. Ott, Kempten, Germany).

\subsection{Statistics}

Data were analysed with Mann-Whitney $U$-tests, except for count data (i.e., data on the number of fish passing the downstream and upstream covered areas), which were analysed with a chi-square goodness-of-fit pairwise test. Significance levels for multiple comparisons were corrected according to a sequential Bonferroni procedure (Rice 1989). Proportion data were also logit-transformed before analysis, in accordance with the method of Sokal and Rohlf (1995). Except for count data, all values were given as mean \pm SE. Results were considered significant if $\alpha<0.05$. Statistical tests were conducted with SPSS 10.0.5 (SPSS Inc., Chicago, IL, USA) for Windows.

\section{Results}

3.1 The relative $U_{\max }$ was identical for both larvae and juveniles, but larvae showed a slower relative $U_{\text {routine }}$ than juveniles

The $U_{\max }$ and the $U_{\text {routine }}$ were 9.4 and $4.6 \mathrm{~cm} \mathrm{~s}^{-1}$ in the larvae, and 25.2 and $16.3 \mathrm{~cm} \mathrm{~s}^{-1}$ in the juveniles, respectively (Fig. 1a, Table 1, $p<0.05$ ), i.e., the larvae swam considerably slower than the juveniles when the swimming speed was
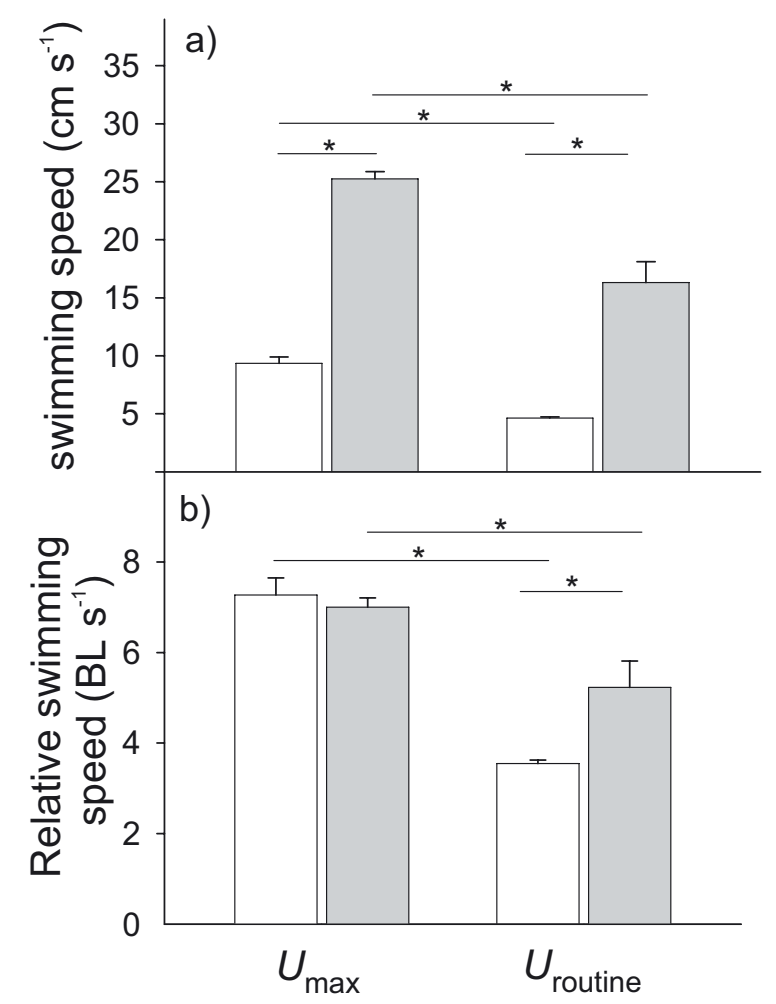

Fig. 1. Swimming speed ( $U_{\max }$ and $U_{\text {routine }}$ ) in larval (white bars) and juvenile (grey bars) fish measured as $\mathrm{cm} \mathrm{s}^{-1}$ (a) and relative swimming speed $\left(B L \mathrm{~s}^{-1} ; \mathrm{b}\right)$. Each bar represents mean $\pm \mathrm{SE} . *$ indicates statistical difference $(p<0.05$; Table 1$)$.

measured in $\mathrm{cm} \mathrm{s}^{-1}$. The relative $U_{\max }$ (i.e., $B L \mathrm{~s}^{-1}$ ), however, did not differ between the larvae and the juveniles (Fig. 1b, Table $1, p<0.05)$. By contrast, the relative $U_{\text {routine }}$ was significantly lower for the larvae than for the juveniles (Fig. 1b, Table $1, p<0.05)$. For both larvae and juveniles, the relative $U_{\max }$ was higher than their respective relative $U_{\text {routine }}$ (Fig. 1b, Table $1, p<0.05)$.

\subsection{Some spawning areas in the River Vidaa may serve as nursery habitats for young North Sea houting}

Comparison of data on swimming performance with those for water speeds in the North Sea houting spawning area in the River Grønaa suggests that water speeds present in $95 \%$ and $85 \%$ of the water column cause a downstream displacement of larvae and juveniles, respectively (Fig. 2). Larvae can maintain position near the river bank in the River Grønaa where the water speed is $1 \mathrm{~cm} \mathrm{~s}^{-1}$ to $2 \mathrm{~cm} \mathrm{~s}^{-1}$ and thus lower than their $U_{\text {routine }}$ (Fig. 2). Only in March 22, 2007 the water speeds were consistently too high for the larvae to resist downstream displacement (Fig. 2). Furthermore, juveniles may utilise current fields further away from the river bank (Fig. 2). The River Sønderaa, by contrast, is unlikely to function as a nursery habitat because its strong currents may subject larvae to downstream displacement (Fig. 2). We did not investigate whether benthic macrophytes or the boundary layer near the river bed provided slow-flowing water. Therefore, the habitat suitable for larval and juvenile fish may be underestimated. 


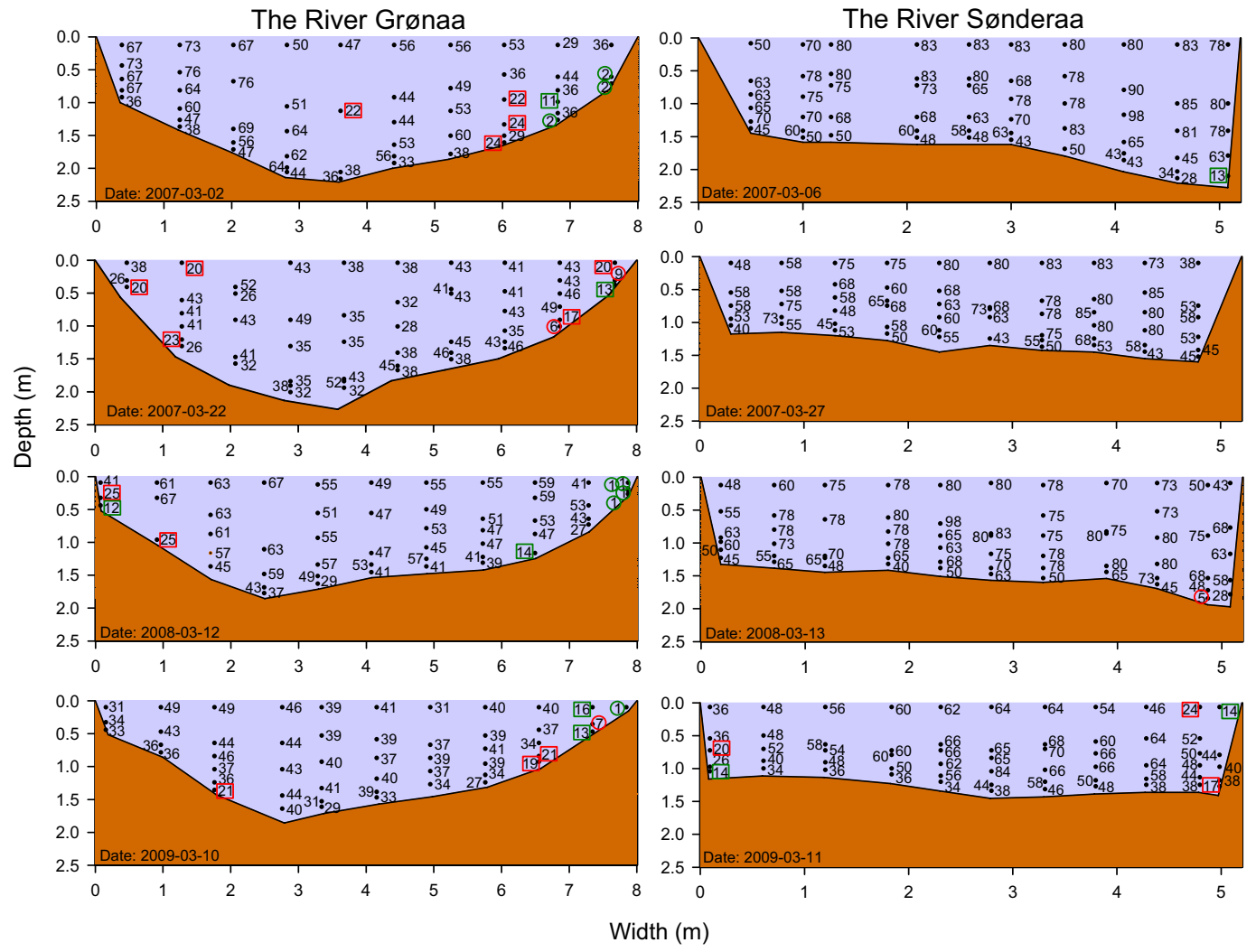

Fig. 2. Water speeds $\left(\mathrm{cm} \mathrm{s}^{-1}\right)$ in the River Grønaa and the River Sønderaa (both belonging to the River Vidaa system) sampled at different dates in each river. Green circle: larvae and juveniles can maintain their position in the current through long periods (water speed $\leqslant U_{\text {routine}}$ ). Red circle: larvae can maintain their position in the current for short periods (water speed $\leqslant U_{\max }$ ), whereas juveniles can maintain their position for long periods (water speed $<U_{\text {routine}}$ ). Green square: juveniles can maintain their position in the current through long periods (water speed $\leqslant U_{\text {routine}}$ ). Red square: juveniles can maintain their position in the current through short periods (water speed $\leqslant U_{\max }$ ).

Table 1. Statistics of swimming performance ( $U_{\max }$ and $U_{\text {routine }}$ (measured as $\mathrm{cm} \mathrm{s}^{-1}$ and body length $\mathrm{s}^{-1}$ )) and dispersal data (control vs. trials with cover providing shade). $P$-values were determined with Mann-Whitney $U$ pairwise comparison test.

\begin{tabular}{|c|c|c|c|c|c|c|}
\hline \multicolumn{5}{|c|}{ Pairwise test } & $d f$ & $p$ value \\
\hline \multicolumn{7}{|c|}{$\begin{array}{l}\text { Swimming performance } \\
\mathrm{cm} \mathrm{s}^{-1}\end{array}$} \\
\hline larva & $U_{\max }$ & vs. & juvenile & $U_{\max }$ & 24 & $<0.001 *$ \\
\hline larva & $U_{\text {routine }}$ & vs. & juvenile & $U_{\text {routine }}$ & 28 & $<0.001^{*}$ \\
\hline larva & $U_{\max }$ & vs. & larva & $U_{\text {routine }}$ & 25 & $<0.001 *$ \\
\hline juvenile & $U_{\max }$ & vs. & juvenile & $U_{\text {routine }}$ & 27 & $0.001 *$ \\
\hline \multicolumn{7}{|c|}{ Body Length $\mathrm{s}^{-1}$} \\
\hline larva & $U_{\max }$ & vs. & juvenile & $U_{\max }$ & 24 & 0.977 \\
\hline larva & $U_{\text {routine }}$ & vs. & juvenile & $U_{\text {routine }}$ & 28 & $0.001 *$ \\
\hline larva & $U_{\max }$ & vs. & larva & $U_{\text {routine }}$ & 25 & $<0.001 *$ \\
\hline juvenile & $U_{\max }$ & vs. & juvenile & $U_{\text {routine }}$ & 27 & $0.003 *$ \\
\hline \multicolumn{7}{|l|}{ Dispersal } \\
\hline larva & control & vs. & larva & cover & 40 & $0.020 *$ \\
\hline juvenile & control & vs. & juvenile & cover & 60 & $0.002 *$ \\
\hline larva & control & vs. & juvenile & control & 50 & $<0.001 *$ \\
\hline larva & cover & vs. & juvenile & cover & 50 & $<0.001^{*}$ \\
\hline
\end{tabular}

* Statistical significance determined with sequential Bonferroni correction $(p<0.05)$.

\subsection{Habitat complexity decreased dispersal, and larvae dispersed slower than juveniles}

Both the larvae and the juveniles increased the time spent in the experimental section before dispersing when they had cover providing shade, compared with when they had no cover (Fig. 3a, Table $1 p<0.05$ ). Furthermore, the larvae spent more time in the experimental section than the juveniles, both in tests with and without cover (Fig. 3a, Table 1, $p<0.05$ ). When cover was present, $65 \%$ of the larvae remained in the experimental section throughout the whole test period (i.e., >2700 s), whereas only $3 \%$ of the juveniles did.

\subsection{Larvae spent a shorter time under the cover than juveniles, and they refused to cross the upstream-positioned covered area}

The larvae spent a smaller percentage of the time under the cover than the juveniles (Fig. 3b, $p<0.05$ ). Furthermore, no larvae crossed the upstream-positioned cover, whereas they passed the downstream cover (Fig. 4a, $p<0.05$ ). The number of larvae passing the upstream-positioned area with the cover was also significantly lower when the cover was present than when it was not (Fig. $4 \mathrm{a}, p<0.05$ ). No such differences were observed for the juveniles (Fig. 4b, $p>0.05$ ). 


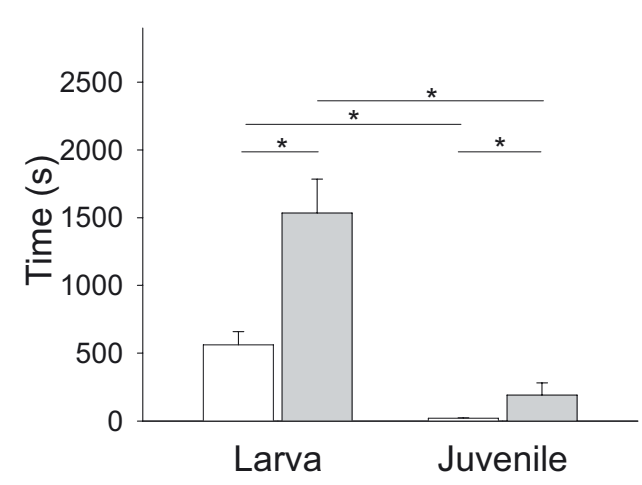

(a)

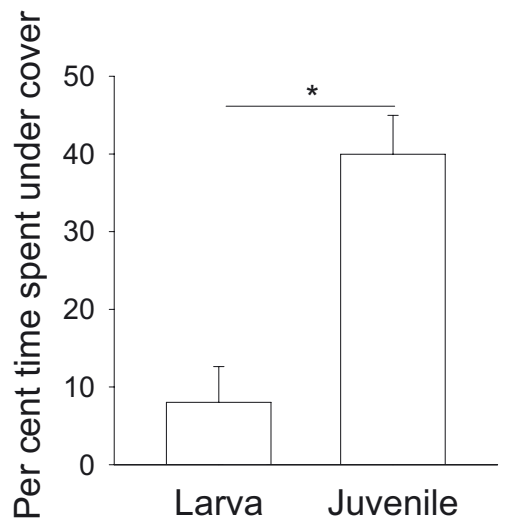

(b)

Fig. 3. Time spent by larvae and juveniles in the experimental section (in an indoor stream channel) before dispersal (s) when covers providing shade were absent (white bars) or present (grey bars) (a). Percentage of time spent under cover (b). Each bar represents mean \pm SE. * indicates statistical difference $(p<0.05$; Table 1$)$.

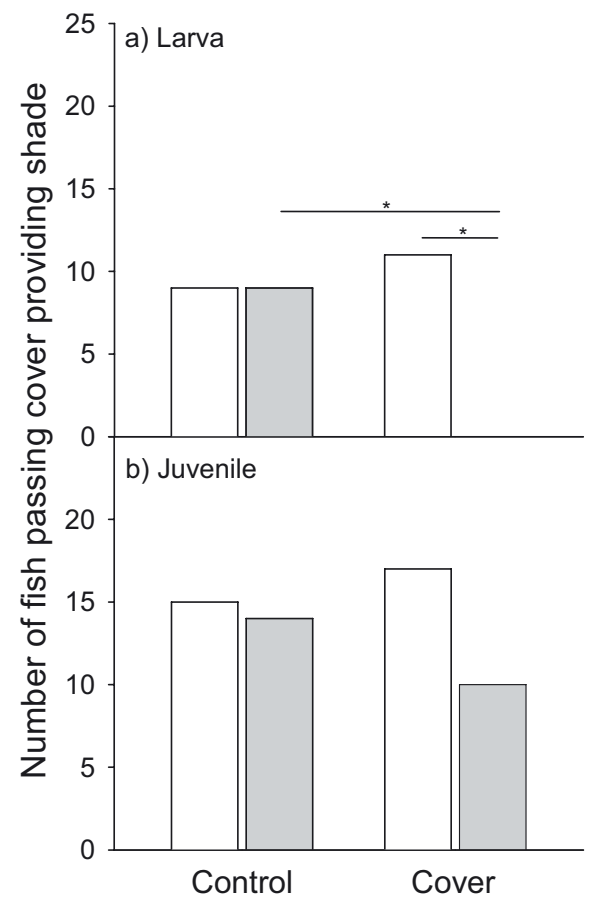

Fig. 4. Number of larvae (a) and juveniles (b) passing downstream (white bars) and upstream (grey bars) covered areas. * Indicates statistical difference $(p<0.05)$.

\section{Discussion}

We provided the first evidence of ontogenetic differentiation of swimming performance and behaviour in the North Sea houting. Both larvae and juveniles performed active positioning behaviour and responded behaviourally when they were presented with habitat modification in the form of cover providing shade (Fig. 3). The larvae, dispersed later and spent less time under the covers than the juveniles. This behaviour was facilitated by their reasonable swimming abilities comparable to that of other fish species (Wolter and Arlinghaus 2003;
Guan et al. 2008; Koumoundouros et al. 2009) shortly after hatching $\left(U_{\max }: 9.4 \mathrm{~cm} \mathrm{~s}^{-1}\left(B L \mathrm{~s}^{-1}: 7.3\right), U_{\text {routine }}: 4.6 \mathrm{~cm} \mathrm{~s}^{-1}\right.$ $\left(B L \mathrm{~s}^{-1}: 3.5\right)$; Fig. 1). These data contradict earlier predictions assuming that larval North Sea houting are inferior swimmers that depend on stagnant water in their nursery habitats (Madsen and Murray 2007).

We related these novel findings to water speed data collected in North Sea houting spawning areas during the egg hatching period (March). In the River Vidaa, larval North Sea houting are exposed to water speeds exceeding their maximum swimming performance in $95 \%$ of the water column (Fig. 2). However, the larvae showed active positioning behaviour in currents $\left(4 \mathrm{~cm} \mathrm{~s}^{-1}\right.$, Fig. 3). Newly-hatched larvae may thus actively seek areas with low water speeds (i.e., $\leqslant U_{\text {routine, }}$ Fig. 2 ). Slow-flowing water near the river bank in the River Grønaa may potentially function as nursery habitat for young North Sea houting. By contrast, strong currents in the River Sønderaa will presumably subject larvae to downstream displacement (Fig. 2).

The construction of an artificial lake (Lake Nørres $\emptyset$ ) in the River Vidaa (Madsen and Murray 2007; Hansen et al. 2008) included assumption-based estimates of the swimming performance of larval and juvenile North Sea houting. These estimates were used in individual-based modelling and hydraulic modelling. The present study is the first to examine the real swimming performance of North Sea houting. Our measurements of $U_{\max }$ and $U_{\text {routine }}$ (Fig. 1) could indeed be applicable in future conservation programs and could serve as valuable parameters to include in habitat suitability modelling and in niche theory (Hirzel and Le Lay 2008).

The relative $U_{\text {routine }}$ was significantly higher in the juveniles than in the larvae (Fig. 1b), a finding that suggests ontogenetic differentiation in the North Sea houting. With the assumption that the $U_{\text {routine }}$ and the optimal relative swimming speed $\left(U_{\text {opt }}\right.$, i.e., the swimming speed where the amount of work per metre is minimised) are comparable (Videler 1993), this result is is in agreement with the work of by Dabrowski et al. (1986). Using measurements of oxygen consumption rates, these authors demonstrated that the relative $U_{\mathrm{opt}}$ is 
considerably higher in juvenile whitefish (Coregonus schinzi palea) than in larval fish. Therefore, juvenile fish maintain a higher relative $U_{\text {routine }}$ than larvae, as shown in the present study. Moreover, we demonstrated that the relative $U_{\text {routine }}$ tended to be closer to the relative $U_{\max }$ in juveniles than in larvae (Fig. 1b). The same trend is evident when comparing $U_{\text {opt }}$ (Dabrowski et al. 1986) with the burst swimming speed ( $U_{\text {burst }}$ ) of another whitefish species, Coregonus clupeaformis (Hoagman 1974). Therefore, the $U_{\text {routine }}$ may be closer to the $U_{\max }$ in juvenile than in larval fish. The downstream migration of juvenile salmonids to the sea has been hypothesised to be due to physiological changes that decrease their swimming performance and that make them unable to maintain their position in lotic environments. However, Peake and McKinley (1998) provided no support for the proposed mechanism, which is presumably not relevant for juvenile North Sea houting either.

Our $U_{\max }$ protocol is suitable for estimating the swimming speeds used during short-term manoeuvring through current fields in rivers (Reidy et al. 2000). The short duration of each stepwise increase in the swimming speed (30 s) allows the fish to rely partly on anaerobic metabolism to cover the swimming costs at speeds approaching $U_{\max }$. By contrast, the conventional critical swimming speed protocol $\left(U_{\text {crit }}\right)$ normally involves $15 \mathrm{~min}$ to $30 \mathrm{~min}$ steps and provides data that are important for examining the long-term aerobic swimming performance of fish (Brett 1964). Therefore, $U_{\text {crit }}$ protocols are mostly relevant for long distance migration and long-term foraging activity (Reidy et al. 2000).

The present study estimated the swimming performance of the North Sea houting in a constant rectilinear flow, a condition used in most studies on swimming performance (e.g., Webb et al. 1984). However, turbulence may influence the swimming performance and the energetics of fish (Enders et al. 2003; Liao et al. 2007; Tritico and Cotel 2010; Taguchi and Liao 2011). Eddy diameter, orientation and vorticity can play important roles in decreasing swimming performance (Tritico and Cotel 2010), so flows that have a component of predictability may attract fish (Liao 2007). Our comparison of swimming performance data with field data (Figs. 1 and 2) did not consider variation in turbulence. Nevertheless, moderate turbulence may increase the predator-prey encounter rate under low prey abundance and increase the growth of fish larvae (MacKenzie and Kiørboe 1995; Mariani et al. 2007; Pécseli et al. 2010). Anneville et al. (2011) showed that whitefish larvae Coregonus lavaretus L. adjust their predatory behaviour (i.e., speed and pursuit) according to the swimming pattern of the prey. Therefore, complex swimming abilities and feeding strategies might be developed during the early ontogeny in North Sea houting larvae. On the basis of these studies and the present swimming performance data (Fig. 1), we speculate that larval North Sea houting might benefit from slow-flowing water, including moderate levels of turbulence, and that habitats with stagnant water might not be preferable.

By using indoor stream channels, we demonstrated that cover induced stationary behaviour and thus reduced the dispersal tendency of larval and juvenile North Sea houting (Fig. 3a). The survival of the houting is assumed to be jeopardised by high water speeds in rivers, which cause arrival at sea before the fish are physiologically adapted to life in seawater (Thomsen 2003; Madsen and Murray 2007; Hansen et al. 2008). Our findings indicate that habitat modifications could help prevent the premature downstream displacement of both larval and juvenile North Sea houting.

The larvae spent less time under cover than the juveniles (Fig. 3b). This finding agrees with previous ones showing that coregonid larvae are positively phototactic and prefer illuminated areas (Fabricius and Lindroth 1954; Lindroth 1957). Similar patterns were reported by studies that investigated ontogenetic differentiation in other fish species (Krause et al. 1998; Dowling and Godin 2002). Ontogenetic differentiation may be a consequence of that larvae have a relatively higher energetic demand than juveniles (Wootton 1994). Therefore, larvae may spend more time in areas suitable for foraging, i.e., outside covered areas (Sih 1997; Krause et al. 1998). The reduced dispersal tendency in larvae (Fig. 3a) might be promoted by avoidance of the covered/shaded areas, whereas in juveniles, it may be a result of the preference of fish for covered areas functioning as refuge.

The water speeds sampled in the River Vidaa (Fig. 2) only represent a fraction of the flow conditions experienced by young North Sea houting in the spawning sites. The comparison of the samples with our laboratory $U_{\max }$ and $U_{\text {routine }}$ estimates (Fig. 1) must therefore be interpreted with caution. The results should be confirmed through an investigation of young North Sea houting under field conditions. The laboratorybased stream channels do not represent the exact field conditions, but they are useful for improving our understanding of behavioural ontogenetic differentiation and in determining the effects of habitat modification. Moreover, the present study focused on identifying the effect of ontogenetic state on dispersal and the use of cover providing shade. Further investigations that address the effects of various light intensities (i.e., night vs. day), threat from piscivores and food density would be of interest.

\section{Conclusion}

This study provides the first evidence of ontogenetic differentiation of the swimming performance and behaviour in the North Sea houting. Both the larval and the juvenile fish performed active positioning behaviour by responding to habitat modifications that provided the opportunity to seek cover. This behaviour was facilitated by reasonable swimming abilities comparable to other fish species, in both larval and juvenile North Sea houting. The comparison of laboratory swimming performance data with water speeds in North Sea houting spawning areas in the River Vidaa shows that in one location, the water speeds present in $95 \%$ and $85 \%$ of the water column would cause a downstream displacement of the larvae and the juveniles, respectively. However, areas near river banks and river beds with slow-flowing water might function as nursery habitats. We suggest that habitat complexity (e.g., cover) may influence the dispersal behaviour in larval and juvenile North Sea houting. Overall, the findings of this work will be valuable for the development and dissemination of science-based conservation strategies.

Acknowledgements. L.F. Jensen was supported by a grant (grant number 2008-7.40.01/56103-0005) from the Heritage Agency of 
Denmark, the Danish Ministry of Culture. J.C. Svendsen was supported by a grant from the Danish Research Council to the research school SLIP and the Fishnet research network. Special thanks go to K. Ricklefs and the staff at the Research and Technology Centre Westcoast, Büsum, Germany as well as K. Aarestrup and J.F. Steffensen. Furthermore, we wish to express our gratitude to U. Siebert, C.B. Thøstesen, H. Malte and J. Aggeboe for additional help on the project. Thanks also go to the staff at the Gesellschaft für Marine Aquakultur (GMA) mbH, Büsum, Germany and the staff at the Fisheries and Maritime Museum, Esbjerg, Denmark. Finally, we thank two anonymous reviewers for their valuable comments.

\section{References}

Aas Ø., Einum S., Klemetsen A., Skurdal J., 2011, Atlantic salmon ecology. Oxford, Wiley, Lucas M.C., Baras E., Migration of freshwater fishes, London, Blackwell Science.

Albrecht H.E., Borys M., Damaschke N., Tropea C., 2003, Laser doppler and phase doppler measurement techniques. Berlin, Heidelberg, New York, Springer.

Anneville O., Berthon V., Glippa O., Mahjoub M.S., Molinero J.C., Souissi S., 2011, Ontogenetic dietary changes of whitefish larvae: insights from field and experimental observations. Environ. Biol. Fishes 91, 27-38.

Bell W.H., Terhune L.D.B., 1970, Water tunnel design for fisheries research. J. Fish. Res. Board Can. Tech. Rep. 195, 1-69.

Bernatchez L., Vuorinen J.A., Bodaly R.A., Dodson J.J., 1996, Genetic evidence for reproductive isolation and multiple origins of sympatric trophic ecotypes of whitefish (Coregonus). Evolution 50, 624-635.

Borcherding J., Scharbert A., Urbatzka R., 2006, Timing of downstream migration and food uptake of juvenile North Sea houting stocked in the Lower Rhine and the Lippe (Germany). J. Fish Biol. 68, 1271-1286.

Brett J.R., 1964, The respiratory metabolism and swimming performance of young sockeye salmon. J. Fish. Res. Board Can. 21, 1183-1226.

Bushnell P.G., Jones D.R., Steffensen J.F., Schurmann H., 1994, Exercise metabolism in 2 species of cod in Arctic waters. Polar Biol. 14, 43-48.

Cattanéo F., Hugueny B., Lamouroux N., 2003, Synchrony in brown trout, Salmo trutta, population dynamics: a "Moran effect" on early-life stages. Oikos 100, 43-54.

Cote J., Fogarty S., Weinersmith K., Brodin T., Sih A., 2010, Personality traits and dispersal tendency in the invasive mosquitofish (Gambusia affinis). Proc. R. Soc. Lond. B. Biol. Sci. 277, 1571-1579.

Crisp D.T., 1991, Stream channel experiments on downstream movement of recently emerged trout, Salmo trutta L., and salmon, $S$. salar L. - III. Effects of developmental stage and day and night upon dispersal. J. Fish Biol. 39, 371-381.

Crisp D.T., Hurley M.A., 1991a, Stream channel experiments on downstream movement of recently emerged trout, Salmo trutta L., and salmon, S. salar L. - I. Effect of four different water velocity treatments upon dispersal rate. J. Fish Biol. 39, 347-361.

Crisp D.T., Hurley M.A., 1991b, Stream channel experiment on downstream movement of recently emerged trout, Salmo trutta L. and salmon, S. salar L. - II. Effect of constant and changing velocities and of day and night upon dispersal rate. J. Fish Biol. 39, 363-370.

Dabrowski K.R., Kok L.Y., Takashima F., 1986, How efficiently do fish larvae and juveniles swim. Comp. Biochem. Physiol. A 85, 657-661.
Dowling L.M., Godin J.G.J., 2002, Refuge use in a killifish: influence of body size and nutritional state. Can. J. Zool. 80, 782-788.

Enders E.C., Boisclair D., Roy A.G., 2003, The effect of turbulence on the cost of swimming for juvenile Atlantic salmon (Salmo salar). Can. J. Fish. Aquat. Sci. 60, 1149-1160.

Etheridge E.C., Adams C.E., Bean C.W., Durie N.C., Gowans A.R.D., Harrod C., Lyle A.A., Maitland P.S., Winfield I.J., 2012, Are phenotypic traits useful for differentiating among a priori Coregonus taxa. J. Fish Biol. 80, 387-407.

Fabricius E., Lindroth A., 1954, Experimental observations on the spawning of whitefish, Coregonus lavaretus L., in the stream aquarium of the Hölle laboratory at River Indalsälven. Rep. Inst. Freshw. Res. Drottningholm 35, 105-112.

Farrell A.P., 2007, Cardiorespiratory performance during prolonged swimming tests with salmonids: a perspective on temperature effects and potential analytical pitfalls. Philos. Trans. R. Soc. B. 362, 2017-2030.

Farrell A.P., 2008, Comparisons of swimming performance in rainbow trout using constant acceleration and critical swimming speed tests. J. Fish. Biol. 72, 693-710.

Freyhof J., Schöter C., 2005, The houting Coregonus oxyrinchus (L.) (Salmoniformes: Coregonidae), a globally extinct species from the North Sea basin. J. Fish Biol. 67, 713-729.

Gehrke P.C., Fidler L.E., Mense D.C., Randall D.J., 1990, A respirometer with controlled water-quality and computerized data acquisition for experiments with swimming fish. Fish Physiol. Biochem. 8, 61-67.

Guan L., Snelgrove P.V.R., Gamperl A.K., 2008, Ontogenetic changes in the critical swimming speed of Gadus morhua (Atlantic cod) and Myoxocephalus scorpius (shorthorn sculpin) larvae and the role of temperature. J. Exp. Mar. Biol. Ecol. 360, 31-38.

Hansen F.T., Rosshaug P.S., Murray C., Madsen M., Kristensen L., Møller B., 2008, Modellering af snæbelynglens migration. Vand \& Jord 15, 1, 23-27 (in Danish).

Heggenes J., Traaen T., 1988, Downstream migration and critical water velocities in stream channels for fry of four salmonid species. J. Fish Biol. 32, 717-727.

Hirzel A.H., Le Lay G., 2008, Habitat suitability modelling and niche theory. J. Appl. Ecol. 45, 1372-1381.

Hoagman W.J., 1974, Vital activity parameters as related to the early life history of larval and post-larval lake whitefish Coregonus clupeaformis. In: Blaxter J.H.S. (eds.), The early life history of fishes, Berlin, Springer, pp. 547-558.

Hvidt C.B., Christensen I.G., 1990, Træk af nordsøsnæblens (Coregonus oxyrhynchus L.) biologi i Vidå-systemet (Master's thesis). Aarhus, the Zoological Laboratory, University of Aarhus (in Danish).

Jacobsen M.W., Hansen M.M., Orlando L., Bekkevold D., Bernatchez L., Willerslev E., Gilbert M.T.P., 2012, Mitogenome sequencing reveals shallow evolutionary histories and recent divergence time between morphologically and ecologically distinct European whitefish (Coregonus spp.). Mol. Ecol., 21, 2727-2742.

Jensen A.J., Johnsen B.O., 1999, The functional relationship between peak spring floods and survival and growth of juvenile Atlantic salmon (Salmo salar) and brown trout (Salmo trutta). Funct. Ecol. 13, 778-785.

Jensen A.R., Ejby-Ernst M., Møller B., Grøn P.N., 2002, Status for bestande af snæbel Coregonus oxyrhynchus i Vadehavsområdet 1989-1998. In: Pihl S., Laursen K. (eds.), Kortlægning af arter omfattet af EF-Habitatdirektivet 1997-2000 (Arbejdsrapport fra DMU nr. 167), Copenhagen, Danish Ministry of the Environment, pp. 15-55 (in Danish). 
Jensen A.R., Nielsen H.T., Ejbye-Ernst M., 2003, National management plan for the houting. Ribe, Danish Ministry of the Environment, Forest and Nature Agency, the County of Sønderjylland and the County of Ribe.

Koumoundouros G., Ashton C., Xenikoudakis G., 2009, Ontogenetic differentiation of swimming performance in Gilthead seabream (Sparus aurata, Linnaeus 1758) during metamorphosis. J. Exp. Mar. Biol. Ecol. 370, 75-81.

Liao J.C., 2007, A review of fish swimming mechanics and behaviour in altered flows. Philos. Trans. R. Soc. Lond. B Biol. Sci. 362, 1973-1993.

Lindroth A., 1957, A study of the whitefish (Coregonus) of the Sundsvall Bay District. Rep. Inst. Freshwater Res. Drottningholm 38, 70-108.

Lucas M.C., Baras E., 2001, Migration of freshwater fishes, London, Blackwell Science.

Krause J., Loader S.P., Kirkman S., Ruxton, G.D., 1999, Refuge use by fish as a function of body weight changes. Acta Ethol. 2, 2934.

Krause J., Loader S.P., McDermott J., Ruxton G.D., 1998, Refuge use by fish as a function of body length-related metabolic expenditure and predation risks. Proc. R. Soc. Lond. B. Biol. Sci. 265, 2373 2379.

Madsen M., Murray C., 2007, Modellering af de hydrauliske konsekvenser samt snæbellarveopvækstbetingelserne ved gennemførelse af snæbelprojekt i Hestholm og Nørres $\varnothing$. Hørsholm, Forest and Nature Agency - Lindet Statsskovdistrikt, Landsdelscenter Sydjylland (in Danish).

MacKenzie B.R., Kiørboe T., 1995, Encounter rates and swimming behavior of pause-travel and cruise larval fish predators in calm and turbulent environments. Limnol. Oceanogr. 40, 1278-1289.

Mariani P., MacKenzie B.R., Visser A.W., Botte V., 2007, Individualbased simulations of larval fish feeding in turbulent environments. Mar. Ecol. Prog. Ser. 347, 155-169.

Mesick C.F., 1988, Effects of food and cover on numbers of apache and brown trout establishing residency in artificial stream channels. Trans. Am. Fish. Soc. 117, 421-431.

Østbye K., Bernatchez L., Næsje T.F., Himberg J.M., Hindar K., 2005, Evolutionary history of the European whitefish Coregonus lavaretus (L.) species complex as inferred from mtDNA phylogeography and gill-raker numbers. Mol. Ecol. 14, 4371-4387.

Østbye K., Amundsen P.-A., Bernatchez L., Klemetsen A., Knudsen R., Kristoffersen R., Naesje T.F., Hindar K, 2006, Parallel evolution of ecomorphological traits in the European whitefish Coregonus lavaretus (L.) species complex during postglacial times. Mol. Ecol. 15, 3983-4001.

Oufiero C.E., Garland Jr T., 2009, Repeatability and correlation of swimming performances and size over varying time-scales in the guppy (Poecilia reticulata). Funct. Ecol. 23, 969-978.

Peake S., McKinley R.S., 1998, A re-evaluation of swimming performance in juvenile salmonids relative to downstream migration. Can. J. Fish. Aquat. Sci. 55, 682-687.

Pécseli H.L., Trulsen J., Fiksen Ø., 2010, Predator-prey contact and capture rates in turbulent water: analytical models and numerical tests. Prog. Oceanogr. 85, 171-179.

Poulsen S.B., Svendsen J.C., Jensen L.F., Schulz C., Jäger-Kleinicke T., Schwarten H., 2010, Effects of food deprivation on refuge use and dispersal in juvenile North Sea houting Coregonus oxyrinchus under experimental conditions. J. Fish Biol. 77, 17021708.

Pusey B.J., Arthington A.H., 2003, Importance of the riparian zone to the conservation and management of freshwater fish: a review. Mar. Freshw. Res. 54, 1-16.
Rasmussen P.C., 2004, Opvækstområder for snæbel i Vidå og Ribe $\AA$ A. Ribe, The County of Sønderjylland, The County of Ribe and Forest and Nature Agency (in Danish).

Rehage J.S., Sih A., 2004, Dispersal behavior, boldness, and the link to invasiveness: a comparison of four Gambusia species. Biol. Invasions 6, 379-391.

Reidy S.P., Kerr S.R., Nelson J.A., 2000, Aerobic and anaerobic swimming performance of individual Atlantic cod. J. Exp. Biol. 203, 347-357.

Rice W.R., 1989, Analyzing tables of statistical tests. Evolution 43, 223-225.

Saltveit S.J., Bremnes T., Lindås O.R., 1995, Effect of sudden increase in discharge in a large river on newly emerged Atlantic salmon (Salmo salar) and brown trout (Salmo trutta) fry. Ecol. Freshw. Fish 4, 168-174.

Sih A., 1997, To hide or not to hide? Refuge use in a fluctuating environment. Trend. Ecol. Evol. 12, 375-376.

Sokal R.R., Rohlf F.J., 1995, Biometry. 3rd edition, New York, W.H. Freeman and Company.

Stoltze M., Pihl S., 1998, Rødliste 1997 over planter og dyr i Danmark, Ministry of the Environment, National Environmental Research Institute and Forest and Nature Agency, Denmark (in Danish).

Taguchi M., Liao J.C., 2011, Rainbow trout consume less oxygen in turbulence: the energetics of swimming behaviours at different speeds, J. Exp. Biol. 214, 428-1436.

Thomsen D.S., 2003, Udvikling af saltvandstolerance hos snæblen (Coregonus oxyrhynchus) (Master's thesis). Aarhus, Institute of Biology, University of Southern Denmark (in Danish).

Tritico H.M., Cotel A.J., 2010, The effects of turbulent eddies on the stability and critical swimming speed of creek chub (Semotilus atromaculatus). J. Exp. Biol. 213, 2284-2293.

Vehanen T., Bjerke P.L., Heggenes J., Huusko A., Mäki-Petäys A., 2000, Effect of fluctuating flow and temperature on cover type selection and behaviour by juvenile brown trout in artificial flumes. J. Fish Biol. 56, 923-937.

Videler J.J., 1993, Fish swimming. 1st edition, London, Chapman \& Hall.

Vonlanthen P., Bittner D., Hudson A.G., Young K.A., Müller R., Lundsgaard-Hansen B., Roy D., Di Piazza S., Largiader C.R., Seehausen O., 2012, Eutrophication causes speciation reversal in whitefish adaptive radiations. Nature 482, 357-362.

Webb P.W., Kostecki P.T., Stevens E.D., 1984, The effect of size and swimming speed on locomotor kinematics of rainbow trout. J. Exp. Biol. 109, 77-95.

Wenger S.J., Isaak D.J., Luce C.H., Neville H.M., Fausch K.D., Dunham J.B., Dauwalter D.C., Young M.K., Elsner M.M., Rieman B.E., Hamlet A.F., Williams J.E., 2011, Flow regime, temperature, and biotic interactions drive differential declines of trout species under climate change. Proc. Natl. Acad. Sci. 108, 14175-14180.

Wilzbach M.A., 1985, Relative roles of food abundance and cover in determining the habitat distribution of stream-dwelling cutthroat trout (Salmo-Clarki). Can. J. Fish. Aquat. Sci. 42, 1668-1672.

Wolter C., Arlinghaus R., 2003, Navigation impacts on freshwater fish assemblages: the ecological relevance of swimming performance. Rev. Fish Biol. Fish. 13, 63-89.

Wootton R.J., 1994, Energy allocation in the threespine stickleback. In: Bell M.A., Foster S.A. (eds.), the evolutionary biology of the threespine stickleback. Oxford, Science Publications, pp. 116-143. 